\title{
Governance of Green Infrastructure. An Analysis of Urban Forests in Metropolitan Areas in Mexico
}

\author{
Miryam HERNÁNDEZ CASTELLANOS, University of Guadalajara - CUAAD, Mexico \\ Juan Ángel DEMERUTIS ARENAS, University of Guadalajara - CUAAD, Mexico
}

\begin{abstract}
This article aims to identify the governance situation in the planning of green infrastructure in metropolitan areas in Mexico, with an emphasis on citizen-led group experiences.

The Guadalajara Metropolitan Area is taken as a reference point - one of the three largest urban agglomerations in the country. Two urban forests in the metropolis are analyzed as case studies, which in recent years have been the object of citizen initiatives that pursue their restoration taking into consideration the state and municipal authorities, but with a project that intends to fill a void that, due to limitations, is not fulfilled by the government. The analysis concludes with recommendations about the innovative elements of citizen initiatives for the management of urban forests, which also promote inclusion and collaboration with social, public, private, and academic sectors. These recommendations may be considered in future metropolitan planning experiences that seek to address mitigation and adaptation to climate change to build resilience in metropolitan areas.
\end{abstract}

\section{Keywords}

Green Infrastructure, Metropolitan Governance, Metropolitan Planning, Climate Change

\section{Introduction}

The population in Mexico has been concentrated in 15 metropolitan areas with more than one million inhabitants. More than $40 \%$ of the total population of the country is located there, and more than $75 \%$ of the national GDP is produced in those areas (SEDATU - CONAPO - INEGI, 2018). They are the main generators of greenhouse gases and consequently, they represent the best possibility of applying measures to mitigate the impacts of climate change. Because they concentrate most of the population, it is essential for these cities to apply adaptation measures to minimize the risks to which their inhabitants could be exposed.

In this context, green infrastructure (GI) takes on special relevance, as it provides numerous ecosystem services (ES) or socio-environmental benefits that are essential for mitigating and adapting to climate change. The understanding and evaluation of these services depends on the implementation of innovative schemes for their management, such as those in which citizens actively intervene, in order to enhance their beneficial effects in the face of the numerous challenges of metropolitan areas.

The purpose of this article is to identify and characterize citizen initiatives around the management of urban forests as GI areas in the Guadalajara Metropolitan Area (GMA) - one of the three most populated in the country, toward generating an impact on the decision-making for planning the $\mathrm{Gl}$ at the metropolitan scale. 
To achieve this objective, a review of the literature focused on the governance of the $\mathrm{Gl}$ is developed in the following section. Subsequently, it is presented the methodology that was followed to analyze the specific case of the GMA from the perspective of active interest groups belonging to the public and social sectors, to then prompt a discussion considering the results of the analysis and finalize with the conclusions.

\section{The Governance of the GI}

GI has a double function in the development of the metropolis; on the one hand, it is a strategic concept for urban and regional planning, and on the other, it has the function of a public policy implementation approach (Wilker et al., 2016). This last connotation has been little explored by research in the world in general and in Mexico in particular, so it is necessary to acknowledge its potential.

Governance originates from a new reality characterized by the government's insufficiency to meet some of the basic needs of the cities (Navarrete Ulloa, 2019); it is linked to the change that the public sector has been going through, from being an entity that provided solutions to all urban problems, to become located in a complex context in which it is impossible, due to its limitations, to meet all those needs. It is pertinent to affirm that no actor is sufficient in complex contexts.

"Public problems are redefined in terms of the insufficiency of traditional government, theoretically validating governance as the response to these conditions" (Aguilar Villanueva, 2016, p. 70). For this reason, the organization of citizens through interest groups created to resolve specific issues has gained increasing importance in solving problems. In fact, it is considered that for issues such as the environmental ones, inter-actor coordination is necessary; in short, a change in the governance arrangement on issues related to natural elements.

According to some authors, participation is guided by the context, which establishes cultural, political, and historical conditions (Luyet, et al., 2012). It is also important to recognize that to achieve successful participations it is crucial to have the support of interest groups through their firm conviction, which usually presupposes a long process to generate trust among participants.

Consequently, interventions that emerge spontaneously but within civil society, will have more value and will be increasingly influential in the governance processes of the $\mathrm{Gl}$ of a metropolis.

\section{Methods}

To identify citizen initiatives in urban forests of the GMA, newspaper articles were reviewed, including publications from January 1, 2016, to December 31,2020, since in that period urban forests became part of public programs; in other words, they were considered on the local agenda. The search included the term 'urban forest'.

In order to focus the analysis particularly on notes referring to the involvement of citizens in the dynamics of urban forests, a filter was made to initially identify and then associate them to specific urban forests in accordance with current planning instruments, that is, the Land Use Plan of the Guadalajara Metropolitan Area (in Spanish, Plan de Ordenamiento Territorial del Área Metropolitana de Guadalajara or POTmet), which considers as such those ecosystems composed of trees and vegetation with dense tree mass (IMEPLAN, 2016, p. 316).

Additionally, another cleaning of the data universe was made by only contemplating urban forests that the metropolitan bureau called the Metropolitan Agency for Urban Forests (AMBU by its Spanish initials) considers that fulfill the characteristics of an urban forest.

\section{¿ isocarp}


Through an exchange with AMBU officials, the activities of this agency were identified, as well as their perception of the important citizen initiatives to locate them, establish a direct communication and apply an interview.

Based on the AMBU recommendations and the initiatives detected in the press analysis, two of them were selected for semi-structured interviews. The interviewees were in the respective urban forests, specifically when they were carrying out activities in them. The observations and comments made by the interviewees were reviewed and contrasted with information obtained in the visits to the sites.

\section{The Guadalajara Metropolitan Area (GMA)}

Governance in the planning of the GMA has been transforming in recent years, particularly with the creation of a local government coordination entity called the Guadalajara Metropolitan Area Planning and Management Institute (IMEPLAN, in its Spanish acronym), which has identified urban forests as fundamental elements to face climate change in the region through the (POTmet). As a result of this action, from IMEPLAN itself the AMBU was created to manage urban forests, whose relevance is also considered in the Climate Action Plan of the Guadalajara Metropolitan Area (PACMetro), to a large extent due to the citizen mobilizations that have demanded attention to these green spaces.

According to the transparency portal of the municipality of Guadalajara, the Metropolitan Agency for Urban Forests is a decentralized public body that seeks to dignify and conserve parks, forests and/or protected natural areas located within the polygon called Guadalajara Natural Protected Area, as well as the improvement of ecosystems with their biodiversity and infrastructure (Municipality of Guadalajara, 2021).

The AMBU was created from the Specific Agreement of Coordination and Metropolitan Association, published on September 17, 2019, and approved in the ordinary session of the Metropolitan Coordination Board of the Metropolitan Area of Guadalajara on December 11, 2018, according to the Agency's website, where it is stated as a unique project in Latin America (AMBU, 2021).

For the purpose of reaching a general approach to the experiences of citizen participation that take place in the urban forests of the GMA, an interview was held with collaborators of the Agency, who also provided information about the ecosystem services of mitigation and adaptation to climate change that these spaces bring to the metropolis.

The interview showed that organized citizen participation has been observed in all spaces, though its nature and degree vary. People are associated by common goals, but some groups have more cohesion than others. Likewise, there are groups that more easily accept the administration and intervention of the AMBU in the spaces, and others that are more reluctant in this regard.

A first example of these groups is the collective that was organized for the creation of the Tlaquepaque Urban Forest (in Spanish, Bosque Urbano Tlaquepaque), which the interviewees define as a proactive, organized group with diverse profiles, which has found its purpose quickly and with which it has established a fluid process.

AMBU officials also referred to the Colectivo Ciudadano Pro Bosque Pedagógico del Agua (Citizen Collective Pro Pedagogical Water Forest), which has held a long-term struggle focused on restoring and sustaining the area also known as Colomos III, with a very clear vision about what they want to achieve in that place.

Although they emphasize that the environmental practices conducted in these spaces are not new and should be adopted by everyone, an innovative factor that distinguishes them is the fact that they are carried out as a group rather than individually. 
When asking about the importance of the presence of citizens in urban forests, the Agency recognizes that it is a decisive factor for the conservation of these places. Even when they note that the experiences in TUF and in Colomos III are different, they comment that both forests exist because there were groups of citizens involved in their creation and/or restoration and conservation.

The officials added that they seek that the quality and management in each of the spaces they administer are the same, aspiring to ensure that the infrastructure and equipment are in excellent condition regardless of their location in the metropolitan area, but respecting the particularities of each forest.

In the second part of the interview, the provision of ecosystem services by urban forests in the GMA was addressed, among which hydrological services stood out, since the Agency has put special emphasis on them. They also referred to the role that urban forests play as a habitat for urban flora and fauna, as well as in the retention and improvement of soils by assisting in the recovery of the microbiome.

Regarding specifically the role of urban forests in the face of climate change, they pointed that the most evident relationship is given by the natural association between trees and the regulation of climate, rain, and soil retention.

In terms of the above, they added that the Agency has been a decisive factor in the adoption of good practices in the municipalities that make up the GMA, to address issues related to climate change in urban areas and demonstrate that it is possible to act in this regard to transmit it both to the different governmental bodies and to the citizens.

In addition to the interview with AMBU officials, during the month of March 2021 a search was carried out in newspapers with the highest circulation in the Guadalajara Metropolitan Area, including publications ranging from January 1, 2016, to December 31, 2020. The search included the term 'urban forest', resulting in $\mathbf{2 0 9}$ hits, or an average of $\mathbf{4 2}$ per year. It is possible to assert that it is a topic that interests the citizens and that it has been frequently addressed by the printed media.

However, not all the news found pointed at the involvement of citizens in the dynamics of urban forests. A total of 137 do refer to or are the product of initiatives generated by organized civil society groups. Of these, 104 alluded specifically to a particular urban forest (76\%) (Table 1).

Among the urban forests that have appeared in newspaper articles, Los Colomos, La Primavera, the entrance of the Bugambilias residential area, El Nixticuil and the Arboledas Sur forest stand out. Some of these, although they are referred to as Urban Forests, do not meet the conditions of one due to their physical characteristics, although interest groups have declared them as such.

Based on the newspaper analysis and the interview with AMBU officials, two case studies were selected to be analysed by reviewing the newspaper articles and an interview with members of the groups that intervene in each urban forest. 


\begin{tabular}{|c|c|c|c|c|c|c|c|}
\hline & Urban Forest & 2016 & 2017 & 2018 & 2019 & 2020 & TOTAL \\
\hline 1 & Arboledas Sur & 0 & 0 & 8 & 0 & 0 & 8 \\
\hline 2 & Ávila Camacho & 0 & 0 & 2 & 2 & 0 & 4 \\
\hline 3 & Barranca de Huentitán & 1 & 0 & 0 & 0 & 0 & 1 \\
\hline 4 & Bugambilias & 3 & 0 & 10 & 5 & 0 & 18 \\
\hline 5 & Cerro de la Reina & 0 & 0 & 1 & 0 & 0 & 1 \\
\hline 6 & La Calma & 0 & 1 & 2 & 0 & 0 & 3 \\
\hline 7 & La Primavera & 4 & 2 & 0 & 9 & 6 & 21 \\
\hline 8 & Los Colomos & 11 & 1 & 8 & 5 & 3 & 28 \\
\hline 9 & Miravalle & 0 & 0 & 1 & 0 & 0 & 1 \\
\hline 10 & Nixticuil & 1 & 4 & 2 & 4 & 0 & 11 \\
\hline 11 & Parque agroecológico & 1 & 0 & 0 & 0 & 0 & 1 \\
\hline 12 & Parque Alcalde & 0 & 0 & 1 & 0 & 0 & 1 \\
\hline 13 & Parque Morelos & 0 & 0 & 1 & 0 & 0 & 1 \\
\hline 14 & Tepopote & 0 & 2 & 0 & 0 & 0 & 2 \\
\hline \multirow[t]{2}{*}{15} & Tlaquepaque & 0 & 0 & 0 & 0 & 3 & 3 \\
\hline & TOTAL & 21 & 10 & 36 & 25 & 12 & 104 \\
\hline
\end{tabular}

Table 1. Hemerographic search with the urban forest concept related to citizen initiatives. January 01,2016 , to December 31, 2020. Source: MURAL, 2016_2020

\subsection{Tlaquepaque Urban Forest (Bosque Urbano Tlaquepaque)}

In one of the case studies, the Tlaquepaque Urban Forest (TUF), the interview was conducted with four members of the citizen collective responsible for its creation. The members of the group were asked questions regarding their integration process for the protection of the area and about the ecosystem services it provides to the metropolis.

Regarding the efforts that they made to recover this space and repurpose it as a green area, they mentioned that the place had been owned by the State Government for 50 years, and on two occasions they tried to carry out projects to turn it into a park; however, despite the requests and actions of the citizens, neither of those were fully materialized.

Over time, the area deteriorated: rubble and waste were deposited there, it was fenced off and used as a parking lot, and in the dry season it lacked moisture and there were fires due to the growing grass. This human manipulation of the land caused the loss of natural elements and began to generate negative effects for the residents, who also report floods and unsafe conditions.

Later, in 2020, a fire in this space regained the attention of the inhabitants near the area in order to rescue it, but they noticed the presence of earth moving machinery. Even when they did not receive information from the town hall, the residents organized themselves until they were informed that a vehicle storage with capacity for 3,000 cars would be built, which caused alarm and led to the involvement of about 100 people interested in recovering the space. 
On May 31, 2020, the residents symbolically appropriated the land, planting about 80 trees, which generated a more consolidated organizational process to perform the maintenance activities of the place. Around fifteen people comprised the group and continued to carry out other actions that favored the recognition of the space as the Tlaquepaque Urban Forest. They made constant visits, community work, surveillance, a garden was created, some areas of the place were painted, talks and virtual workshops on various topics have been held, among other activities.

The group also held meetings with government agencies such as IMEPLAN, the General Coordination of Territory Management of the state government, as well as with the state governor. By the month of August (Mural, 2020), the state government announced that it would invest 23 million pesos in the rehabilitation of the plot, to turn it into an urban forest.

Among the conditions that allowed the intervention in the space to be viable, is its assessment as a green area, since previously two park projects had been proposed. It was also important to collect data on air quality and air pollution in the area, as well as information on the lack of urban trees and green areas in the municipality of Tlaquepaque.

Data was also available on noise pollution due to the main roads that run on the limits of the forest, the documented risk on the effect of the heat island in the municipality, the partial plans that did not allow the construction of a vehicular storage, as well as the fact that the forest is located on one side of the highway to Chapala, which constitutes the entrance to the Guadalajara Metropolitan Area from the airport, along with its proximity to the main highway that leads to Mexico City, therefore a park represented a greater landscape value for these main roads.

The residents acknowledge that the COVID-19 pandemic was also a relevant factor that led to the establishment of the forest. Because they were at home, they had more time available to dedicate themselves to take care of the space and allowed for greater communication among them. In addition, they mentioned that many people from the surrounding neighborhoods started to come to the area to walk around and distract themselves from the isolation, attending to the corresponding sanitary measures.

Regarding the characteristics of the Tlaquepaque Urban Forest, the interviewees assert that its extension covers 10,5 hectares. Although the natural elements of the land have suffered many alterations, it is being planned the reforestation of the space with a list of appropriate species for the area provided by the AMBU, which include guamuchiles, mesquites, kidneywoods, white lead trees, tepehuajes, pink trumpet trees, among others. These new trees will help restore the soil, facilitate water infiltration, and serve as habitat for the local fauna.

In relation to the ES that the urban forest provides, and which have been identified by the members of the collective, the following are listed:

\begin{tabular}{|l|l|}
\hline \multicolumn{2}{|c|}{ Ecosystem Services (ES) } \\
\hline - Soil restoration & $-\quad$ Recharge of aquifers \\
\hline$-\quad$ Reduction of noise pollution & $-\quad$ Habitat of flora and fauna species \\
\hline - Decreased heat island effect & $-\quad \begin{array}{l}\text { Food production in the community garden } \\
\text { at the beginning of the project }\end{array}$ \\
\hline - Oxygen generation and CO2 capture & $-\begin{array}{l}\text { Physical, recreational, cultural, } \\
\text { educational activities }\end{array}$ \\
\hline
\end{tabular}

Table 2. ES listed by the Tlaquepaque Urban Forest citizen collective. Source: own elaboration based on interviews 
Additionally, the group implemented a Clean Point in the space, where they initially produced compost and currently continue to carry out collection and revaluation of plastic, electrical, aluminum, cardboard, and electronic waste. With this initiative, they have accomplished to manage about 15 tons of waste, and they plan to expand their capacity with new containers.

During these and other activities, the group has established collaboration networks with various stakeholders, such as some government agencies, the private sector, civil organizations, and some schools.

Their future objectives include: 1) Reaching the consolidation of the forest and continuing to participate as a group in decision-making; 2) Acquiring more tools and materials for the operation of the space; and 3) Sustaining the operation of the clean point with the involvement of the community to have a positive impact on waste management, which has become a hallmark of the community and of the Tlaquepaque Urban Forest.

Respecting the importance of citizens being involved in the management of urban forests, the members of the group interviewed consider that the appropriation of these spaces and the sense of belonging of the users towards the space contribute to creating conditions of security, as well as the constant care and maintenance of the place.

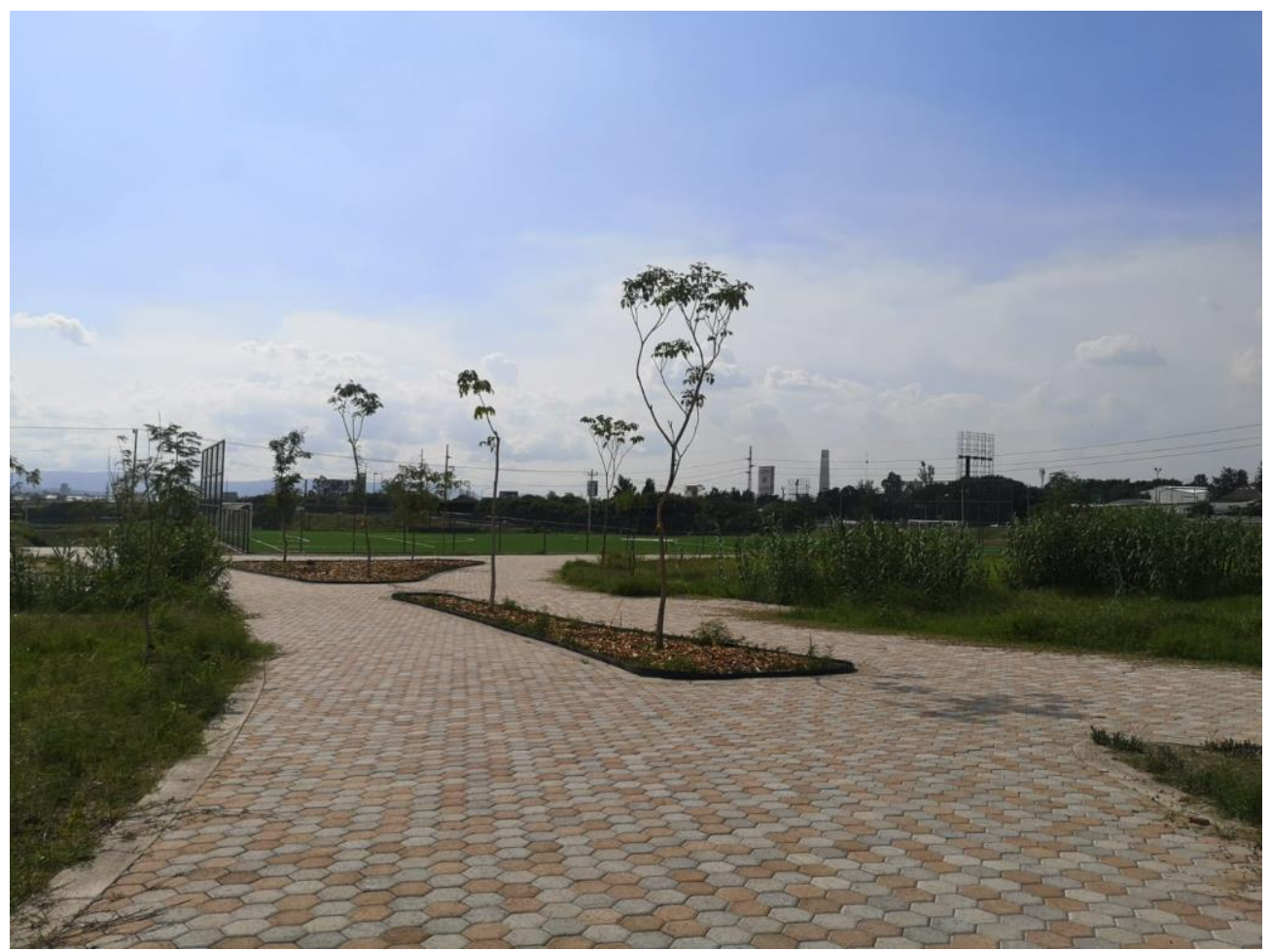

Illustration 1. View of the Tlaquepaque Urban Forest. Source: own illustration

\subsection{Pedagogical Water Forest (Bosque Pedagógico del Agua)}

The Citizen Collective Pro Pedagogical Water Forest (Colomos III) is probably the oldest of the groups that have intervened urban forests in the GMA. In the newspaper search carried out, some statements by their representatives stand out, who since 2016 have highlighted the latent threat that the urban development represents for the forest, given that the surrounding soil had increased exponentially in value due to the emergence of high-profile urbanizations.

In the interview conducted with members of the collective, it was mentioned that affiliates of various groups had undertaken protective actions in the area. Ciudadanos por el Medio Ambiente (Citizens for the Environment) identified a portion of land that was acquired by the State Government at the 
beginning of the 20th century for hydrological protection, with whose plans it was possible to reach grounds of approximately 36 hectares, in which there were streams and the La Campana spring, so it was determined to work for its conservation.

Hence, work began on the cleaning and maintenance of the area, with the first forest plantation activities taking place in 1998. In 2004, they aimed at gaining leverage on the State Congress to issue a declaration of a protected natural area that was granted in 2007 to the Colomos I and II sections, in the municipality of Guadalajara. Nonetheless, it was not until 2013 and 2014 that the declarations for Colomos III were issued by the Zapopan City Council and the State Congress, respectively.

Also in 2013, the space was called the Pedagogical Water Forest (Bosque Pedagógico del Agua, in Spanish), thus revealing its mission as a school forest, with an educational vocation with and for water. It was in the same year that the Colectivo Ciudadano Pro-Bosque Pedagógico del Agua (CCproBPA) emerged.

According to Gutiérrez Rosete (2019), some of the activities encompassed by the CCproBPA are those related to the restoration of the space in accordance with a management plan that is collectively prepared, evaluated and updated. Periodic meetings are also held with public agencies; volunteers and social service providers are accepted. Cultural and environmental education events, guided tours, along with other activities are organized as well. Internally, the group regularly holds coordination meetings, training workshops and feedback exercises, besides other efforts.

All the above is included in the participatory forest restoration methodology, which has been aimed at promoting a model of native urban forest. According to the members of the group who were interviewed, this model seeks to facilitate conditions to restore a forest by respecting the complex functions and interconnections between the forest, soil, and water. Among the fundamental principles of this model are working with native species, not using sophisticated technological implements to take advantage of local resources and those obtained through donations, avoiding as far as possible the construction of concrete structures or the use of agrochemicals, and more.

Within the Pedagogical Water Forest there are different areas, of which these stand out: 1) Pine or pineoak areas; 2) Riparian vegetation such as willow, ahuehuete or ash next to bodies of water; 3 ) Deciduous Forest.

Since the group promotes a comprehensive vision of the forest, they do not employ the concepts of ecosystem services or natural resources, but because they consider them more encompassing, they speak of the socio-environmental benefits provided by the means of nature to sustain life. Among them, they distinguish the following:

\begin{tabular}{|cl|}
\hline \multicolumn{2}{|c|}{ Socio-environmental benefits } \\
\hline- & Climate regulation \\
\hline- & Hydrological protection \\
\hline- & Reduction of noise pollution \\
\hline- & Carbon capture and oxygen generation \\
\hline- & Propagation of native flora and fauna \\
\hline- & Leisure and educational activities \\
\hline - & Soil conservation \\
\hline
\end{tabular}

Table 3. Socio-environmental benefits listed by the Citizen Collective Pro Pedagogical Water Forest. Source: own elaboration based on interviews 
Regarding climate change, they comment that they have observed numerous effects, such as periods of increasingly intense low water, the recent appearance of the bark beetle and other pests; lower availability of water that generates hydric stress in the vegetation and decrease in the survival of planted trees, and a higher level of uncertainty and extreme situations in terms not only of drought, but also of precipitation which, associated with other factors such as urbanization, cause loss of soil and trees.

In view of this and other effects, the group has organized itself to conduct its activities while they seek to value and strengthen their autonomy conditions in a multidimensional sense: political, economic, scientific-technological, cultural, legal, and so on. Although the collective pursues non-subordination; its members emphasize that they maintain the capacity for discussion and horizontal dialogue, which is why they have found support in some governmental instances, recognizing the role that different people can have in various governments.

Furthermore, they assert that they have established collaborative networks with diverse grassroots groups that work in the defense and restoration of other wooded and forestry spaces in the GMA, as well as with organized and unorganized neighborhood groups, broader social movements, and civil organizations of diverse nature. They also keep in touch with private sector companies, adding that there has been a long partnership with schools and universities.

Finally, they highlight the importance of the link between academia and social participation, mentioning that the analysis of the problems should not be separated from the generation of alternatives. In this sense, they conclude by stating that the restoration process and the organization process have sustained a close relationship, since the collective has been a school, not only to be taught how to restore a native urban forest, but also to learn how to be organized collectively, which is a fundamental element that exalts the pedagogical character of this experience.

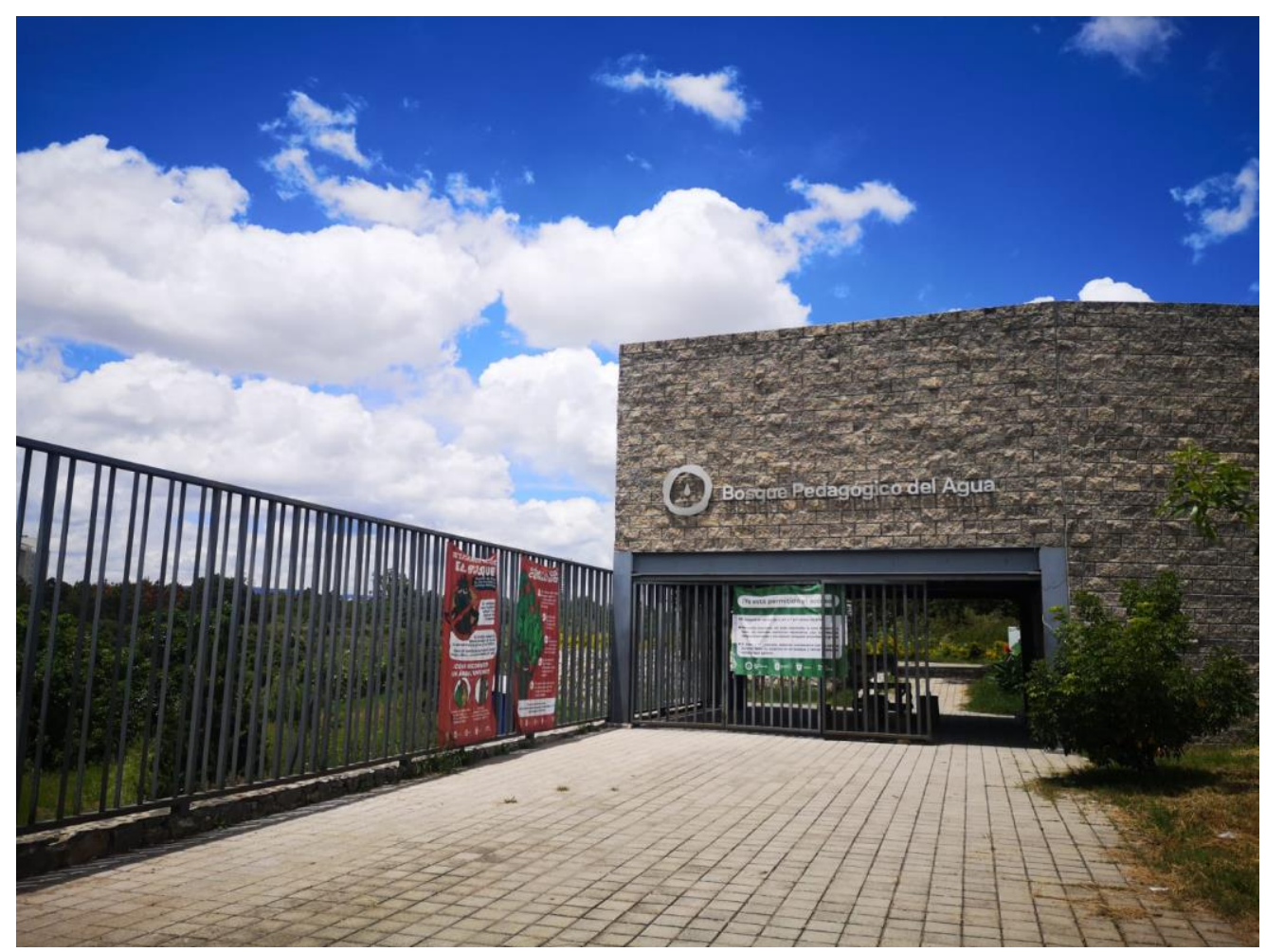

Illustration 1. View of the Pedagogical Water Forest. Source: own illustration 


\section{Discussion and Conclusions of the Analysis}

The evidence found through the review of newspaper articles and the interviews applied to the interest groups, allow us to envision a bright future for the urban forests of the GMA, considering that both dimensions of the Green Infrastructure, as a factor of strategic planning and as a space for implementation of policies, are firmly present in the metropolis.

The arrival of organized citizen groups to fill the gaps left by public authorities has allowed Gl and the Ecosystem Services it provides to be conserved for the benefit not only of the immediate neighbors of the forests, but also for all citizens, so the opinions and work of these citizen groups must be heard and respected for the successful management of urban forests.

It is interesting to observe that citizen initiatives are presented both to perform actions for the conservation and consolidation of existing urban forests (Pedagogical Water Forest) and to take steps toward creating new urban forests on land areas which had not been granted this use (Tlaquepaque Urban Forest).

Additionally, it is also important to note that in both cases these are state-owned lands in which the municipalities together with citizens have performed interventions, the majority promoted by the members of the citizen groups who are presented as key actors for the Gl governance in the GMA.

As regards the ES or socio-environmental benefits identified by the citizen groups in urban forests, it is relevant to note than we can find among them some that are very important for mitigation and adaptation to climate change (Quiroz Benítez, 2018). However, it is equally advisable to carry out a more detailed evaluation to get to know in depth the contributions that these spaces provide.

It is pertinent to point out that the Tlaquepaque Urban Forest and the Pedagogical Water Forest are not the only urban forests in the GMA where citizen participation takes place, and in this sense, it would be worth characterizing other experiences in future studies. However, the above are clear examples of the scope that organized citizens can have in terms of protection and restoration of areas that represent numerous benefits to face climate change in metropolises.

Considering the lessons that the COVID-19 pandemic has left us, it will be very valuable to continue looking at and supporting the collective actions that emerge as alternatives to influence in an innovative way the many metropolitan challenges that we have at our doorstep, to build fair, resilient, and desirable realities.

\section{References}

Aguilar Villanueva, L. F., 2016. Democracia, gobernabilidad y gobernanza. CDMX: Instituto Nacional Electoral.

AMBU, 2021. Agencia de Bosques Urbanos. [Online] Available at: https://bosquesurbanos.mx/transparencia/inciso/61/

Benedict, M. A. \& McMahon, E. T., 2001. Green instrastructure: Smart conservation for the 21st century. Washington, D.C.: Sprawl Watch Clearinghouse.

Gerlak, A. K. et al., 2021. Agency and governance in green infrastructure policy adoption and change. Journal of Environmental Policy \& Planning, pp. 1-17.

Gómez-Baggethun, E. et al., 2013. Urban ecosystem services. In: Urbanization, biodiversity and ecosystem services: Challenges and oportunities. Dordrecht: Springer Netherlands, pp. 175-251. 
Gutiérrez Rosete, J. G., 2019. Aprender a restaurar, aprender a organizarnos. El caso del Colectivo Ciudadano Pro Bosque Pedagógico del Agua. REMEA - Revista Eletrônica do Mestrado em Educação Ambiental, October.pp. 209-227.

IMEPLAN, 2016. Instituto Metropolitano de Planeación (IMEPLAN). [Online] Available at: https://www.imeplan.mx/sites/default/files/IMEPLAN/POTmet_IIIFB-BajaRes.pdf [Accessed 2021].

Luyet, V., Schlaepfer, R., Parlange, M. B. \& Buttler, A., 2012. A framework to implement Stakeholder participation in environmental projects. Journal of Environmental Management, Issue 111, pp. 213-219.

Municipio de Guadalajara, 2021. Municipio de Guadalajara. [Online]

Available at:

https://transparencia.guadalajara.gob.mx/sites/default/files/iniciativas/2020/PresidenteSindica Noviembre.pdf

MURAL (2016_2020). MURAL. [Online]

Available at: https://www.mural.com.mx/ [Accessed March 2021].

Navarrete Ulloa, C. A., 2019. Modelo de gobernanza metropolitana en México. Principios generales para la definición de hechos metropolitanos y su medición. In: Modelos y políticas públicas de la gobernanza metropolitana. Guadalajara, Jalisco: El Colegio de Jalisco, pp. 33-52.

Quiroz Benítez, D. E., 2018. México - Gobierno de la República. [Online]

Available at:

https://www.gob.mx/cms/uploads/attachment/file/394115/Hoja_de_ruta_IV_Infraestructura_V erde.pdf

SEDATU - CONAPO - INEGI, 2018. Delimitación de las zonas metropolitanas de México 2015. CDMX: SEDATU-CONAPO-INEGI.

Wilker, J., Rusche, K. \& Rymsa-Fitschen, C., 2016. Improving Participation in Green Infrastructure Planning. Planning Practice \& Research, pp. 229-249. 